\title{
Contract research organization commentary on the importance of harmonization and the impact of ICH M10
}

\author{
Chad Briscoe*, ${ }^{*}$ Corey Nehls², Mike Buonarati ${ }^{3}$, Stephanie Cape ${ }^{4}$, Rafiqul Islam ${ }^{5}$, Christina \\ Satterwhite ${ }^{6}$ \& Roger Hayes ${ }^{7}$ \\ ${ }^{1}$ PRA Heath Sciences, Lenexa, KS 66219, USA \\ 2 PPD, Wilmington, NC 28401, USA \\ ${ }^{3}$ Intertek Pharmaceutical Services, LCMS, San Diego, CA 92121, USA \\ ${ }^{4}$ Covance Laboratories Inc., Bioanalytical Chemistry, Madison, WI 53704, USA \\ ${ }^{5}$ Celerion Inc., 621 Rose Street, Lincoln, NE 68502, USA \\ ${ }^{6}$ Charles River Laboratories, Wilmington, MA 01887, USA \\ ${ }^{7}$ ICON plc, Whitesboro, NY 13492, USA \\ *Author for correspondence: BriscoeChad@prahs.com
}

"In order to have a more unified voice and the opportunity to discuss controversial regulatory and scientific issues in a noncompetitive, noncommercial environment, the Bioanalytical CROs formed the Global CRO Council”"

First draft submitted: 21 August 2019; Accepted for publication: 6 September 2019; Published online: 26 September 2019

Keywords: bioanalysis $\bullet \mathrm{CRO} \bullet \mathrm{GCC} \bullet$ global $\bullet$ guidance $\bullet$ harmonization $\bullet \mathrm{ICH}$ M10 $\bullet$ validation

Global harmonization of best practices in bioanalysis has been a goal within the bioanalytical industry for quite a number of years, dating back as far as the first so-called 'Crystal City' meeting in 1990. That meeting, sponsored by the American Association of Pharmaceutical Scientists along with the US FDA, started the development of the initiative to introduce consistent guidelines across the regulated bioanalytical industry. These efforts ultimately lead to a White Paper summarizing the conference outcome and subsequent release of the 2001 FDA guidance document $[1,2]$, which significantly harmonized bioanalytical validations industry wide. Subsequent guidance documents [3-9] have been generated and added to or clarified validation requirements, but also introduced minor but notable differences in study conduct. The release of the first draft global regulatory Guideline on Bioanalytical Method Validation from the International Council for Harmonization of Technical Requirements for Pharmaceuticals for Human Use (ICH) in February of 2019 [10] will be able to further harmonize bioanalytical validations and sample analysis studies, and provide for a more consistent understanding of global regulatory expectations. The release of this draft guidance and ultimately its finalization will have tremendous positive implications across the regulated bioanalysis segment of the pharmaceutical industry. There are many stakeholders including Pharmaceutical Developers, Regulators and the Contract Research Organizations (CROs). Each has a unique perspective on their drivers for a globally harmonized, properly written and well understood global guideline.

In order to have a more unified voice and the opportunity to discuss controversial regulatory and scientific issues in a noncompetitive, noncommercial environment, the Bioanalytical CROs formed the Global CRO Council (GCC) on 14 September 2010 [11]. In that time, the group has published opinions on many important topics in regulated bioanalysis and the group has become a recognized voice in the industry for any bioanalytical CROs who choose to participate in the organization [12-26]. The organization is unique in that it is committed to every member having an equal voice. As such, each meeting is organized as a true round table discussion with meetings taking place around a literal round table accommodating often more than 50 members representatives. The egalitarian nature of the organization is truly unique, and it works to foster open and honest communication from all who choose to be involved. 
In today's drug development industry, the bioanalytical CROs conduct the majority of the regulated bioanalytical testing to support drug development. Therefore, their input into the ICH M10 guidance is critical. This along with the GCC's growing voice in the global bioanalytical community created an expectation of both the CRO members and others outside of the CRO community that the GCC would provide an opinion and response to the recently released ICH M10 Draft Guideline. As the GCC is unique in its structure, the members also chose to be unique in their approach to reviewing and commenting on the document. The approach of the GCC's response which is presented in an article in this issue of Bioanalysis [27] was to break the document into seven subsections, identify leaders and teams for each section and then review the document line by line. The discussions were framed by a line-by-line survey of member companies which the teams then reviewed and discussed in a morning meeting session of the GCC and then presented back to the full GCC meeting in an afternoon session for further discussion and alignment. The summary of the above referenced survey and the conclusions from this 12-h meeting which took place on 5 April 2019 in New Orleans (LA, USA) is how the core material for the article was generated.

Several members of the GCC who led the ICH M10 discussion teams were happy to provide personal thoughts and commentary on the ICH M10 and participated in the featured interview series on the journal's sister site, Bioanalysis Zone [28].

Financial \& competing interests disclosure

The authors have no relevant affiliations or financial involvement with any organization or entity with a financial interest in or financial conflict with the subject matter or materials discussed in the manuscript. This includes employment, consultancies, honoraria, stock ownership or options, expert testimony, grants or patents received or pending, or royalties.

No writing assistance was utilized in the production of this manuscript.

\section{References}

1. Shah VP, Midha KK, Dighe S et al. Analytical methods validation: bioavailability, bioequivalence and pharmacokinetic studies: sponsored by the American Association of Pharmaceutical Chemists, U.S. Food and Drug Administration, Fédération Internationale Pharmaceutique, Health Protection Branch (Canada) and Association of Official Analytical Chemists. Int. J. Pharm. 82(1-2), 1-7 (1992).

2. US Department of Health and Human Services, US FDA, Center for Drug Evaluation and Research, Center for Veterinary Medicine. Guidance for industry, bioanalytical method validation (2001). www.fda.gov/downloads/Drugs/Guidance/ucm070107.pdf

3. EMA. Committee for medicinal products for human use (CHMP). Guideline on bioanalytical method validation (2011). www.ema.europa.eu/docs/en_GB/document_library/Scientific_guideline/2011/08/WC500109686.pdf

4. US Department of Health and Human Services, US FDA, Center for Drug Evaluation and Research, Center for Veterinary Medicine. Guidance for industry, bioanalytical method validation (2018). www.fda.gov/regulatory-information/search-fda-guidance-d ocuments/bioanalytical-method-validation-guidance-industry

5. ANVISA. Resolution RDC 27 minimum requirements for bioanalytical method validation used in studies with the purpose of registration and post-registration of medicines. Agencia National de Vigilancia Sanitaria,

Brazil (2012). http://pesquisa.in.gov.br/imprensa/jsp/visualiza/index.jsp?jo rnal=1\&pagina=93\&data=22/05/2012

6. Japanese Ministry of Helath, Labour \& Welfare. Guideline on bioanalytical method validation in pharmaceutical development (2013). www.nihs.go.jp/drug/BMV/250913_BMV-GL_E.pdf

7. Japanese Ministry of Helath, Labour \& Welfare. Guideline on bioanalytical method (ligand binding assay) validation in pharmaceutical development (2014). www.nihs.go.jp/drug/BMV/260530_LBA-GL_E.pdf

8. Health Canada, Bureau of Pharmaceutical Sciences Therapeutic Products Directorate. Notice: clarification of bioanalytical method validation procedures (2015). www.canada.ca/en/health-canada/services/drugs-health-products/drug-products/announcements/notice-c larification-bioanalytical-method-validation-procedures.html

9. Health Canada, Bureau of Pharmaceutical Sciences Therapeutic Products Directorate. Addendum to notice: clarification of bioanalytical method validation procedures (2016). www.canada.ca/en/health-canada/services/drugs-health-products/drug-products/announcements/ notice-clarification-bioanalytical-method-validation-procedures.html\#a 1

10. International Council for harmonisation of technical requirements for pharmaceuticals for human use. ICH harmonised guideline. Bioanalytical method validation M10 (2019). www.ich.org/fileadmin/Public_Web_Site/ICH_Products/Guidelines/Multidisciplinary/M 10/M10EWG_Step2_DraftGuideline_2019_0226.pdf

11. Premkumar N, Lowes S, Jersey J et al. Formation of a global contract research organization council for bioanalysis. Bioanalysis 2(11), 1797-1800 (2010).

12. Lowes S, Jersey J, Shoup R et al. Recommendations on: internal standard criteria, stability, incurred sample reanalysis and recent $483 \mathrm{~s}$ by the Global CRO Council for Bioanalysis. Bioanalysis 3(12), 1323-1332 (2011). 
13. Breda N, Garofolo F, Cruz Caturla M et al. The 3rd Global CRO Council for Bioanalysis at the International Reid Bioanalytical Forum. Bioanalysis 3(24), 2721-2727 (2011).

14. Boterman M, Doig M, Breda M et al. Recommendations on the interpretation of the new European Medicines Agency Guideline on Bioanalytical Method Validation by Global CRO Council for Bioanalysis (GCC). Bioanalysis 4(6), 651-660 (2012).

15. Lowes S, Jersey J, Shoup R et al. Conference report: 4th Global CRO Council for Bioanalysis: coadministered drugs stability, EMA/US FDA Guidelines, 483s and carryover. Bioanalysis 4(7), 763-768 (2012).

16. Sangster T, Maltas J, Struwe P et al. Recommendations on ISR in multi-analyte assays, Qa/bioanalytical consultants and GCP by Global CRO Council for Bioanalysis (GCC). Bioanalysis 4(14), 1723-1730 (2012).

17. Lowes S, Boterman M, Doig M et al. GCC recommendations on bioanalytical method stability implications of co-administered and co-formulated drugs. Bioanalysis 4(17), 2117-2126 (2012).

18. Nicholson R, Lowes S, Caturla MC et al. Sixth GCC focus on LBA: critical reagents, positive controls and reference standards; specificity for endogenous compounds; biomarkers; biosimilars. Bioanalysis 4(19), 2335-2342 (2012).

19. Hougton R, Gouty D, Allinson J et al. Recommendations on biomarker bioanalytical method validation by GCC. Bioanalysis 4(20), 2439-2446 (2012).

20. Lowes S, LeLacheur R, Shoup R et al. Recommendations on incurred sample stability (ISS) by GCC. Bioanalysis 6(18), 2385-2390 (2014).

21. Rocci M, Lowes S, Shoup R et al. 7th GCC Insights: incurred samples use; fit-for-purpose validation, solution stability, electronic laboratory notebook and hyperlipidemic matrix testing. Bioanalysis 6(20), 2713-2720 (2014).

22. Bower J, Fast D, Garofolo F et al. Eighth GCC: consolidated feedback to US FDA on the 2013 draft FDA guidance on bioanalytical method validation. Bioanalysis 6(22), 2957-2963 (2014).

23. Hayes R, LeLacheur R, Dumont I et al. Ninth GCC Closed Forum: CAPA in regulated bioanalysis; method robustness, biosimilars, preclinical method validation, endogenous biomarkers, whole blood stability, regulatory audit experiences and electronic laboratory notebooks. Bioanalysis 8(6), 487-495 (2016).

24. Cape S, Islam R, Nehls C et al. The 10th GCC Closed Forum: rejected data, GCP in bioanalysis, extract stability, BAV, processed batch acceptance, matrix stability, critical reagents, ELN and data integrity and counteracting fraud. Bioanalysis 9(7), 505-516 (2017).

25. Islam R, Briscoe C, Bower J et al. Eleventh GCC Closed Forum: cumulative stability; matrix stability; immunogenicity assays; laboratory manuals; biosimilars; chiral methods; hybrid LBA/LCMS assays; fit-for-purpose validation; China Food and Drug Administration bioanalytical method validation. Bioanalysis 10(7), 433-444 (2018).

26. Islam R, Kar S, Ritzén H et al. Recommendations for classification of commercial LBA kits for biomarkers in drug development from the GCC for bioanalysis. Bioanalysis 11(7), 645-653 (2019).

27. Nehls C, Buonarati M, Cape S et al. GCC consolidated feedback to ICH on the 2019 ICH M10 Bioanalytical method validation draft guideline. Bioanalysis 11(18), (2019).

28. Bioanalysis zone (2019). www.bioanalysis-zone.com 
